\title{
Patrimônio Geo-Mineiro: quando a interrelação entre eles se evidencia
}

\author{
Geo-Mining Heritage: when the interrelation between them is evidenced
}

Paulo de Tarso Amorim Castro

Geólogo, Universidade Federal de Ouro Preto, Brasil

ptacastro@gmail.com

\begin{abstract}
Resumo
Este artigo faz uma análise sobre a relação existente entre patrimônio mineiro e geopatrimônio. Em face a segmentação existente entre patrimônio cultural e natural, estudos sobre o patrimônio mineiro e geopatrimônio traçaram caminhos paralelos. O conceito de paisagem, que agrega o aspecto natural e cultural faz um elo entre os dois conceitos patrimoniais. Parte-se do princípio que a geomorfologia antropogênica, sobretudo aquela relacionada às atividades mineiras, pode fazer aflorar aspectos da geodiversidade relevantes para o entendimento da história evolutiva regional. É proposta uma classificação de patrimônio geomineiro em três tipos com base na intensidade e extensão das alterações antrópicas sobre as geoformas.
\end{abstract}

Palavras-chave: geopatrimônio, patrimônio mineiro, geomorfologia antropogênica.

\begin{abstract}
This paper analyzes the relationship between mining heritage and geoheritage. Due to the existing segmentation between cultural and natural heritage, studies on mining heritage and geoheritage have traced parallel paths. The concept of landscape, which adds the natural and cultural aspect, makes a link between the two heritage concepts. It is assumed that anthropogenic geomorphology, especially related to mining activities, may outcrops about important aspects of geodiversity in order to the understanding of regional evolutionary history. It is proposed a classification of geomining heritage in three types based on the intensity and extent of anthropic changes on geoforms.
\end{abstract}

Keywords: geoheritage, mining heritage, anthropogenic geomorphology.

\section{INTRODUÇÃO}

A mineração remonta aos princípios da civilização. Há registros desta atividade em diversas culturas e povos. Registros de mineração com mais de 41.000 estão presentes no Egito (VERMEERSCH et al., 1994) e na Suazilândia (BEAUMONT, 1973). Mesmo na América Latina, há registros pré-colombianos, cerca de 12.000 anos, no Chile (SALAZAR et al., 2011). É grande a sua importância como base para a expressão artística, produção de alimentos agrícolas e nucleação de populações. O reconhecimento de sua importância pode ser expresso pela sua representação no rol dos sítios reconhecidos pela UNESCO como Patrimônio Cultural da Humanidade. Muitos núcleos urbanos que se encontram bem preservados ao longo da era cristã tem sua origem diretamente ou indiretamente relacionada à mineração. Em Minas Gerais, por exemplo, os núcleos históricos de Ouro Preto e Diamantina são reconhecidos como patrimônio cultural da humanidade. Outros núcleos urbanos, como Djenné, no Mali, que se estabeleceu como importante centro 
comercial na rota do ouro trans-saariana, também são reconhecidos como patrimônio cultural da humanidade.

No Brasil, além do casario, da cultura e costumes dos habitantes de núcleos urbanos criados em função da presença e extração de recursos minerais, ainda restam preservados registros das atividades mineiras, quer sejam em superfície, quer sejam em subsuperfície. A extração de recursos minerais pode culminar por modificar a paisagem regional e expor rochas, que outrora não afloravam, recobertas que estavam sob solo e vegetação. Nestes casos, a atividade mineira pode resultar em exposições rochosas incomuns, de relevância e com significado geopatrimonial. Em outros casos, o material geológico extraído é que se mostra importante sob ponto de vista geológico. Em ambos os casos, há uma forte relação entre a atividade mineira, por vezes com relevância em termos de patrimônio mineiro, e o geopatrimônio. Este artigo traz reflexões sobre a relação entre o geopatrimônio e o patrimônio mineiro.

\section{CONCEITUAÇÕES DO GEOPATRIMÔNIO E DO PATRIMÔNIO MINEIRO E SUAS CONEXÕES}

Passado mais de um quarto de século das primeiras iniciativas relacionadas aos estudos de geodiversidade, geoconservação e geopatrimônio (REYNARD; BRILHA, 2018) estes termos se consolidaram na comunidade acadêmica. Para os propósitos deste texto será utilizado o termo geopatrimônio como os elementos da geodiversidade que tem relevância na geoconservação, isto é, aqueles de excepcional significância, sejam eles objetos geológicos e feições geomorfológicas e paisagens, sejam eles os processos geradores de tais feições e objetos (BRILHA 2018).

Registros de mineração se encontram em diversas partes do planeta e em diferentes épocas, envolvendo desde os primórdios da humanidade a utilização de materiais geológicos como recursos que assegurassem a sobrevivências de agrupamentos humanos, sua cultura e arte (CASTRO; MACHADO, 2015). Toda o material de natureza geológica, além do valor econômico, cultural e artístico, possui significado para humanidade sob o ponto de vista científico, didático, paisagístico e patrimonial e social (MATA-PERELLÓ et al., 2012).

Os registros relevantes da atividade de mineração, dada a sua relação com a sociedades humanas, são importantes sob o ponto de vista arqueológico e histórico. Neste aspecto se consolida o Patrimônio Mineiro, conceito desenvolvido na Europa, precursora na sua fundamentação, legislação e iniciativas, destacando-se as iniciativas espanholas na regulamentação e nos avanços relacionados ao tema.

O patrimônio mineiro, inicialmente se restringia aos registros arqueológicos da mineração romana e árabe na Europa. Posteriormente, avança mais no período medieval e moderno enfocando 
nas estruturas edificadas e escavações, e nos instrumentos empregados no processo minerário, quer seja em museus urbanos, quer seja in situ, em minas-museus. Ao final do século XX, documentos e elementos imateriais reconhecidos por um segmento da sociedade por seus valores históricos, culturais ou sociais (PUCHE RIART, 2000).

Há uma vertente geológica do que pode ser considerado patrimônio mineiro por um segmento social, constituindo uma conexão com elementos da geodiversidade, (que podem ser reconhecidos como geopatrimônio), estabelecendo uma categoria bivalente patrimonial: 0 patrimônio geológico e mineiro (CAÑIZARES RUIZ, 2011).

\section{OS SÍTIOS RECONHECIDOS COMO PATRIMÔNIO DA HUMANIDADE PELA UNESCO: A DESCONEXÃO ENTRE O PATRIMÔNIO MINEIRO E O GEOPATRIMÔNIO}

A UNESCO (Organização das Nações Unidas para a Educação, a Ciência e a Cultura) mantém uma listagem de todos os sítios considerados como patrimônio da humanidade. Atualmente a lista contém 1092 sítios considerados Patrimônio da Humanidade. Os critérios de avaliação elencados pela UNESCO para que um sítio possa ser considerado Patrimônio da Humanidade estão mostrados no Quadro1. Os seis primeiros critérios estão relacionados como quesitos de análise para sítios que representem o patrimônio cultural, ao passo que os demais se referem ao patrimônio natural da humanidade.

Migori (2018) faz uma revisão e discussão dos critérios e procedimentos utilizados na submissão de solicitações para que sítios de importância em geoconservação sejam considerados como patrimônio da humanidade. Apresenta dados a respeito de patrimônios da humanidade concernentes à geodiversidade e sua combinação com outros elementos naturais. Dos 1073 sítios do patrimônio mundial em 2017, havia 206 sítios classificados pelos seus aspectos naturais. Destes, 90 $(43,7 \%)$ continham referências ao geopatrimônio. Há alguns sítios classificados como patrimônio da humanidade em que foram tomados por base tanto critérios culturais, quanto critérios naturais, apresentados, compondo um sistema misto de elegibilidade.

Foi realizado um levantamento do número de sítios patrimônio da humanidade que apresentam valores patrimoniais da mineração classificados como patrimônio cultural e também como mistos, na listagem apresentada da Unesco de 2018, composta por 1092 sítios, dos quais 845 são culturais e 38 são mistos Existem 28 sítios patrimônio da humanidade em que o patrimônio mineiro é relevante, o que corresponde a $2,56 \%$ dos sítios registrados pela UNESCO. Todos estes sítios foram enquadrados como patrimônio da humanidade somente por aspectos culturais (critérios de 1 a 6, no Quadro1), não havendo nenhum classificado por critérios mistos (englobando os 
critérios culturais e naturais). A distribuição dos critérios utilizados para atribuir o título de patrimônio da humanidade aos registros de mineração estão mostrados na Figura 1.

Quadro 1 - Critérios de elegibilidade de sítios a serem considerados como patrimônio da Humanidade.

\begin{tabular}{|c|c|}
\hline \multicolumn{2}{|c|}{ Patrimônio Cultural } \\
\hline Critério & Descrição \\
\hline 1 & representar o gênio e a criatividade humana \\
\hline 2 & $\begin{array}{l}\text { exibir um importante intercâmbio da valores humanos, durante um período de tempo ou em uma área cultural } \\
\text { do mundo, no desenvolvimento da arquitetura, ou tecnologia, artes monumentais, planejamento urbano ou } \\
\text { design paisagístico }\end{array}$ \\
\hline 3 & ser único ou excepcional testemunho de tradições culturais ou de civilização existente ou desaparecida \\
\hline 4 & $\begin{array}{l}\text { ser um importante exemplo de tipo de construção, arquitetura ou paisagem que ilustre um significativo } \\
\text { estágio na história da humanidade }\end{array}$ \\
\hline 5 & $\begin{array}{l}\text { ser um excelente exemplo de um assentamento humano tradicional, uso da terra ou uso do mar que seja } \\
\text { representativo de uma cultura (ou culturas) ou interação humana com o meio ambiente, especialmente } \\
\text { quando se tornou vulnerável sob o impacto de mudanças irreversíveis }\end{array}$ \\
\hline 6 & $\begin{array}{l}\text { estar direta ou tangivelmente associado a eventos ou tradições vivas, com ideias ou com crenças, com obras } \\
\text { artísticas e literárias de notável significado universal }\end{array}$ \\
\hline \multicolumn{2}{|c|}{ Patrimônio Natural } \\
\hline Critério & Descrição \\
\hline 7 & conter fenômenos naturais superlativos ou áreas de excepcional beleza natural e importância estética \\
\hline 8 & $\begin{array}{l}\text { serem exemplos notáveis que representam os principais estágios da história da Terra, incluindo o registro da } \\
\text { vida, processos geológicos significativos em andamento no desenvolvimento de formas terrestres ou } \\
\text { características geomórficas ou fisiográficas significativas }\end{array}$ \\
\hline 9 & $\begin{array}{l}\text { ser exemplos notáveis que representem processos ecológicos e biológicos em curso na evolução e } \\
\text { desenvolvimento de ecossistemas e comunidades terrestres, de água doce, costeira e marinha de plantas e } \\
\text { animais }\end{array}$ \\
\hline 10 & $\begin{array}{l}\text { conter os habitats naturais mais importantes e significativos para a conservação in situ da diversidade } \\
\text { biológica, incluindo os que contêm espécies ameaçadas de valor universal excepcional do ponto de vista da } \\
\text { ciência ou da conservação }\end{array}$ \\
\hline
\end{tabular}

Fonte: https://whc.unesco.org/en/list/

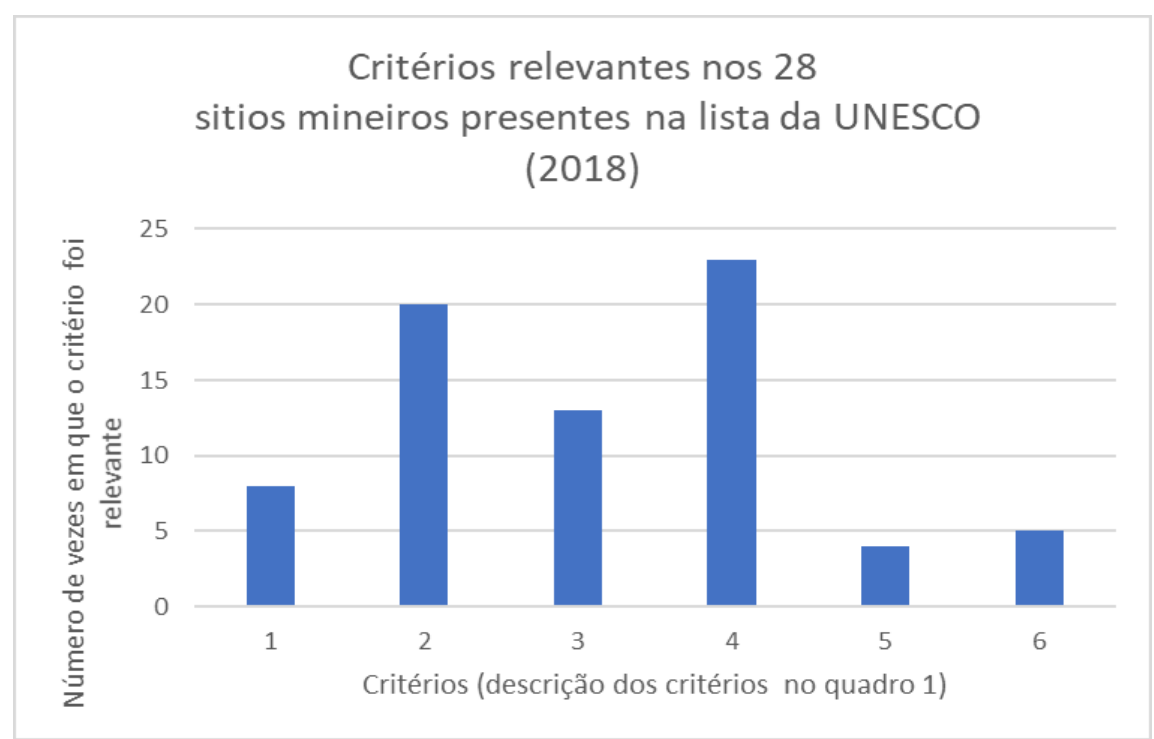

Figura 1 - Distribuição dos critérios relevantes na designação de sítios mineiros como de Sítios Patrimônio da Humanidade UNESCO. 
Os critérios mais frequentes são o 2 (exibir um importante intercâmbio da valores humanos, durante um período de tempo ou em uma área cultural do mundo, no desenvolvimento da arquitetura, ou tecnologia, artes monumentais, planejamento urbano ou design paisagístico) e o 4 (ser um importante exemplo de tipo de construção, arquitetura ou paisagem que ilustre um significativo estágio na história da humanidade). Estes dois critérios, quando aplicados ao patrimônio mineiro indicam que o desenvolvimento de técnicas, a arquitetura e a paisagem são elementos importantes no reconhecimento da relevância para a classificação como patrimônio mundial.

Dentre os 38 sítios patrimônio da humanidade eleitos em sistema misto de classificação, não há nenhum que registre a presença nítida de atividades mineiras e conectadas a geodiversidade. Talvez a ausência destas relações reflita à pouca compreensão acerca das relações entre a mineração, enquanto atividade cultural (e da cultura industrial) e a geologia, enquanto expressão natural.

\section{EXPANDINDO O CONCEITO DE PATRIMÔNIO GEOMINEIRO A PARTIR DO CONCEITO DE PAISAGEM}

As conceituações de patrimônio mineiro e patrimônio geológico (geopatrimônio), ao serem analisadas em conjunto, levam a compreensão de que elementos da geodiversidade podem ser expostos devido à atividade extrativa mineral. Em regiões onde predominam climas úmidos como no sudeste do Brasil, as escavações expõem rochas menos intemperizadas e de rara visão de seus detalhes em afloramentos naturais. Minerais de tamanhos e características incomuns são expostos nas paredes das galerias de abertas para a extração de minerais gemológicos em pegmatitos, veios auríferos tornam-se realçados em galerias de minas de ouro. Rochas, feições estruturais e relações estratigráficas tornam-se visíveis nas bancadas das minas a céu aberto. Em Portugal, no Geopark Arouca, em Canelas, uma pedreira de ardósia em lavra expõe fósseis das maiores trilobitas conhecidas. Eles são recuperados na pedreira e colocados no Centro de Interpretação Geológica de Canelas (GUTIÉRREZ-MARCO et al., 2009). Estes exemplos pontuais mostram, por vezes, a interdependência entre a exposição de sítios da geodiversidade com potencial geopatrimonial e as atividades de mineração.

Nascimento et al. (2013, p.104) analisam a relação entre o patrimônio mineiro e o geopatrimônio, dentro das perspectivas de valores relevantes a um segmento social, do seguinte modo "O patrimônio mineiro é um patrimônio misto: material no que diz respeito ao natural que é geológico e paisagístico, histórico no que se traduz industrial e arquitetônico, tecnológico e documental e imaterial tanto cultural como também histórico centrado na memória, na cultura, nas 
artes e no trabalho, ou seja, na natureza da relação dos grupamentos mineiros e garimpeiros comas rochas".

\subsection{O conceito de paisagem mineira}

Paisagem é um conceito que tem diversas definições, sendo objeto de análises epistemológicas profundas. Está para além dos objetivos deste texto avançar sobre a discussão conceitual. O objetivo é enfocar na paisagem como o elo de conexão entre geopatrimônio e patrimônio mineiro, subsidiando a conceituação de patrimônio geomineiro.

Sob o ponto de vista da geografia física o conceito de paisagem incorpora a interação entre a sociedade e a superfície da geosfera ao longo dos tempos (VITTE, 2007). Deriva desta interrelação o conceito de paisagem patrimonial, uma paisagem a ser protegida, posto ter significado identitário para um agrupamento humano, ou por instituições, que reconhecem diversos atributos, como por exemplo, seus atributos artísticos, simbólicos e técnicos, como significativos e associados a estas comunidades (ZAMORA, 2001). Decorre deste conceito que parte de um patrimônio mineiro pode abarcar - para além das instalações, técnicas, registros e cultura mineiras a paisagem mineira, enquanto interação entre a expressão cultural-industrial de uma comunidade e o natural, representado pela geomorfologia local. Puche Riart (2003) define a paisagem mineira como sendo uma parte do território onde tenha sido realizada atividades extrativas de recursos de natureza geológica.

\subsection{A paisagem antropogênica e a geomorfologia antropogênica}

Em um sentido mais amplo, a paisagem mineira é uma paisagem afetada intensamente pelas ações antrópicas, que, no caso da indústria extrativa, são intensivas pontualmente e impactantes extensivamente. Paisagem antropogênica é uma expressão difundida por Sotchava (1977) para expressar as vulnerabilidades do sistema natural a impactos causados pelas tecnologias humanas. Estas ações intensas transformam as geoformas, interferindo diretamente nos processos geomorfológicos. Disto resulta o entendimento consubstanciado nos últimos vinte anos do século $\mathrm{XX}$, de que as ações antrópicas podem ser modificadoras das geoformas naturais (NIR, 1983; GOULDIE, 1993), fundamentando o conceito de Geomorfologia Antropogênica (SZABÓ et al., 2010). No que tange à classificação das atividades extrativas mineiras as geoformas antropogênicas geradas seriam do tipo de origem direta. 


\section{O PATRIMÔNIO GEOMINEIRO COMO REFLEXO DA GEOMORFOLOGIA ANTROPOGÊNICA}

O foco principal deste texto se relaciona à possibilidade de que os efeitos antrópicos sobre as geoformas, causados pelos intensivos processos de mineração, podem resultar em exposições de feições geológicas significativas que, de outra forma, não estariam disponíveis ao acesso humano. Neste sentido, é possível caracterizar o patrimônio geomineiro vinculado à geomorfologia antropogênica como sendo paisagens geradas ou expostas pelas atividades humanas intensivas, como são as extrações de recursos minerais, que são reconhecidas como significativas sob ponto de vista geológico ou geomorfológico por instituições voltadas aos estudos geopatrimoniais. A depender da relação entre as comunidades humanas que habitam uma região pode haver relações identitárias com estas feições, reforçando o significado patrimonial da paisagem.

\subsection{Tipificação do patrimônio geomineiro vinculado à geomorfologia antropogênica}

Este trabalho propõe uma classificação do patrimônio geomineiro vinculado à geomorfologia antropogênica em três tipos, em função do grau ou intensidade de criação das geoformas antropogênicas, suas dimensões, sua localização em relação aos centros urbanos e a possibilidade de reafeiçamento/reaqualificação de uso. São eles: tipo 1 - paisagem local requalificável; tipo 2 - paisagem regional fortemente modificada pelas atividades mineiras e tipo 3 paisagem regional exumada pela atividade mineira.

O tipo 1, paisagem local requalificável, é entendida como originada pelas modificações causadas pelas atividades mineiras, normalmente negativas (no sentido utilizado por Szabó et al., 2010), constituindo-se da cavas e frentes de lavras locais. Normalmente se encontram encerradas as atividades mineiras, por exaustão do recurso mineral, ou por terem sido englobas pelo crescimento urbano e desativadas em função dos riscos e danos ambientais que causam. A requalificação da paisagem é factível e desejável visando o seu aproveitamento como áreas de turismo e lazer.

O tipo 2, paisagem regional fortemente modificada pelas atividades mineiras, se caracteriza por ser fruto de atividade mineira dispersa em uma região, com escavações, desmontes mineiros e aquedutos, modificando em diferentes intensidades a geomorfologia em função da viabilidade extrativa e à disponibilidade de insumos utilizáveis à extração mineral. A dispersão das modificações antrópicas das geoformas é condicionada pela difusão regional do recurso mineral, sua forma de ocorrência, normalmente em filões ou veios, abundância do recurso e ao seu preço. Devido à dispersão regional deste tipo de recursos minerais em uma região, a requalificação regional em muitas vezes não se mostra viável. 
O tipo 3, paisagem regional exumada pela atividade mineira, demonstra a intensidade da atividade extrativa em uma região e a persistência do processo minerário ao longo do tempo. Normalmente, os recursos minerais nas regiões em que ocorre a exumação da paisagem se concentram a pouca profundidade da superfície natural, e sua extração não requer grandes esforços industriais. A superfície exumada pela atividade antrópica é caracterizada por uma descontinuidade geológica (estratigráfica) bem conspícua, e que marca claramente a separação entre materiais geológicos que apresentam características coesivas e concentrações minerais díspares.

O Quadro 2 apresentada exemplos dos três tipos de patrimônio geomineiro vinculados à geomorfologia antropogênica.

Quadro 2 - Tipificação de Patrimônio Geomineiro vinculado à Geomorfologia Antropogênica.

\begin{tabular}{|c|c|c|c|}
\hline Tipo & Exemplos & Localização & Referência \\
\hline \multirow{5}{*}{$\begin{array}{l}1 \text { - Paisagem local } \\
\text { requalificável }\end{array}$} & Parque das Mangabeiras & Belo Horizonte (MG) & Ruchkys et al. (2012) \\
\hline & Instituto Inhotim & Brumadinho (MG) & Ruchkys et al. (2018) \\
\hline & Pedreira Cumbe & Ouro Preto (MG) & $\begin{array}{l}\text { Ruchkys (2007); Maciel } \\
\text { (2014) }\end{array}$ \\
\hline & Pedreira Tanguá & Curitiba (PR) & Liccardo et al. (2008) \\
\hline & Parque das Pedreiras & Curitiba (PR) & Liccardo et al. (2008) \\
\hline \multirow{4}{*}{$\begin{array}{l}2 \text { - Paisagem regional } \\
\text { fortemente modificada } \\
\text { pelas atividades } \\
\text { mineiras }\end{array}$} & Serra de Ouro Preto & $\begin{array}{l}\text { Ouro Preto e Mariana } \\
\text { (MG) }\end{array}$ & $\begin{array}{c}\text { Sobreira (2014); } \\
\text { Nascimento (2016) }\end{array}$ \\
\hline & Serra de Antônio Pereira & $\begin{array}{l}\text { Ouro Preto e Mariana } \\
\text { (MG) }\end{array}$ & Nascimento (2016) \\
\hline & Bacia do Gandarela & Santa Bárbara (MG) & Maizatto (2001) \\
\hline & Las Médulas & $\begin{array}{l}\text { El Bierzo -Castilla e } \\
\text { León (ES) }\end{array}$ & $\begin{array}{c}\text { Sánchez-Palencia et al. } \\
(1998)\end{array}$ \\
\hline \multirow{2}{*}{$\begin{array}{l}3 \text { - Paisagem regional } \\
\text { exumada pela } \\
\text { atividade mineira }\end{array}$} & Igatu & Andaraí (BA) & $\begin{array}{l}\text { Russ \& Nolasco (2012); } \\
\text { Nolasco (2012) }\end{array}$ \\
\hline & Cerro del Hierro & $\begin{array}{c}\text { San Nicolás del Puerto - } \\
\text { Andaluzia (ES) }\end{array}$ & Moreno et al. (2008) \\
\hline
\end{tabular}

Serão descritos alguns exemplos dos tipos de patrimônio geomineiro vinculado à geomorfologia antropogênica.

O tipo 1 tem vários representantes espalhados pelo mundo. Com a expansão das cidades e os efeitos da globalização nos países centrais, muitas das cavas de minas e pedreiras tornam-se econômica e socio-ambientalmente inviáveis, sendo, por fim, desativadas. A Pedreira Tanguá, em Curitiba é um exemplo destacado deste tipo (Figura 2). Trata-se de uma pedreira que durante décadas municiou a cidade de Curitiba de rochas para os calçamentos e construções. A ações de requalificação da pedreira valorizaram a existência dos paredões e túneis onde estão expostos 
gnaisses e diabásios, aproveitaram a cavidade e estabilizaram o lençol freático, criando um conjunto harmônico e arrojado para fruição da população (LICCARDO et al., 2008).
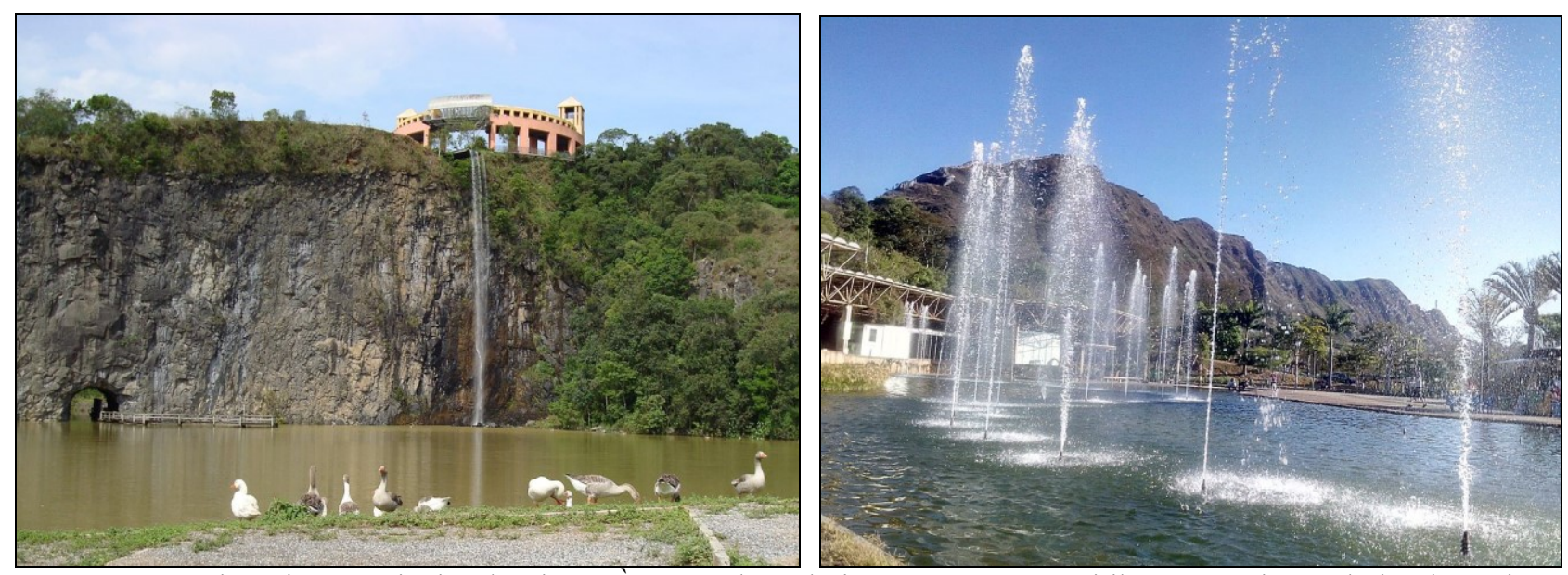

Figura 2 - Patrimônio Geomineiro do Tipo1. À esquerda Pedreira Tanguá, em Curitiba uma antiga pedreira de gnaisses e diabásios requalificada ao uso turístico, preservando a exposição de rochas (foto Leonardo Stabile). À direita Parque das Mangabeiras, em Belo Horizonte, requalificando uma antiga extração de minério de ferro ao sopé da Serra do

Curral (foto Eliezer Costa).

A requalificação de áreas mineradas exauridas e sua incorporação como elemento paisagístico, não necessariamente valorizando os processos e instalações mineiras, os aproxima da conceituação apresentada por Nascimento et al. (2013). São exemplos o Parque Municipal das Mangabeiras, em Belo Horizonte e, parcialmente, o Instituto Inhotim, no município mineiro de Brumadinho (RUCHKYS et al., 2018). Matá-Perelló et al. (2018) argumentam que o uso do patrimônio geomineiro em minas exauridas por meio do turismo pode minimizar os impactos e evitar a depopulação regional.

O tipo 2 se desenvolve em geoformas de maior expressão em área com os trabalhos mineiros removendo expressivos volumes de rochas, modificando a paisagem. Sua expressão se faz por meio de uma atividade extrativa dispersa, uma vez que o recurso mineral ocorre concentrado em veios, filões e camadas, de pouca espessura e com controles estratigráficos e estruturais, Sua concentração e a dispersão em área são grandes. Na maioria das vezes, este tipo está associado a materiais geológicos que possuem alto valor, como o ouro e a prata, explorados em períodos anteriores à revolução industrial. Devido à rigidez locacional dos recursos minerais, quando afastadas das regiões com concentrações urbanas e facilidades viárias os mineradores culminavam por criar vilas, distribuindo as construções e caminhos por entre os locais de trabalho extrativo. Dois exemplos são apresentados: o de Las Médulas, no nordeste da Espanha (Figura 3) e o da Serra de Ouro Preto, em Minas Gerais (Figura 4).

Em Las Médulas ocorreu uma extração de ouro realizada pelos romanos, na fronteira entre a Galícia, Astúrias e Castela e León, no Noroeste da Espanha, nos primeiro e segundo séculos da 
era cristã. Foram minerados depósitos do tipo placer em rochas neogênicas de cerca de 20 Milhões de anos (PROBIERZ, 2012). Os trabalhos mineiros atingiram uma área de 1200 hectares, tendo sido removidos cerca de 100 milhões de $\mathrm{m}^{3}$ (SANCHEZ-PALENCIA et al., 2000), compondo uma paisagem geomineira que é reconhecida como um sítio Patrimônio da Humanidade, devido análise por critérios culturais pela UNESCO. Redondo-Veja et al. (2015) descrevem um carste exumado pelo processo mineração de ouro nos depósitos tipo placer que cobriram a área mais ocidental do vale de La Batoula, em Las Médulas. No entanto, os registros de exumação não se distribuem por toda região de mineração.

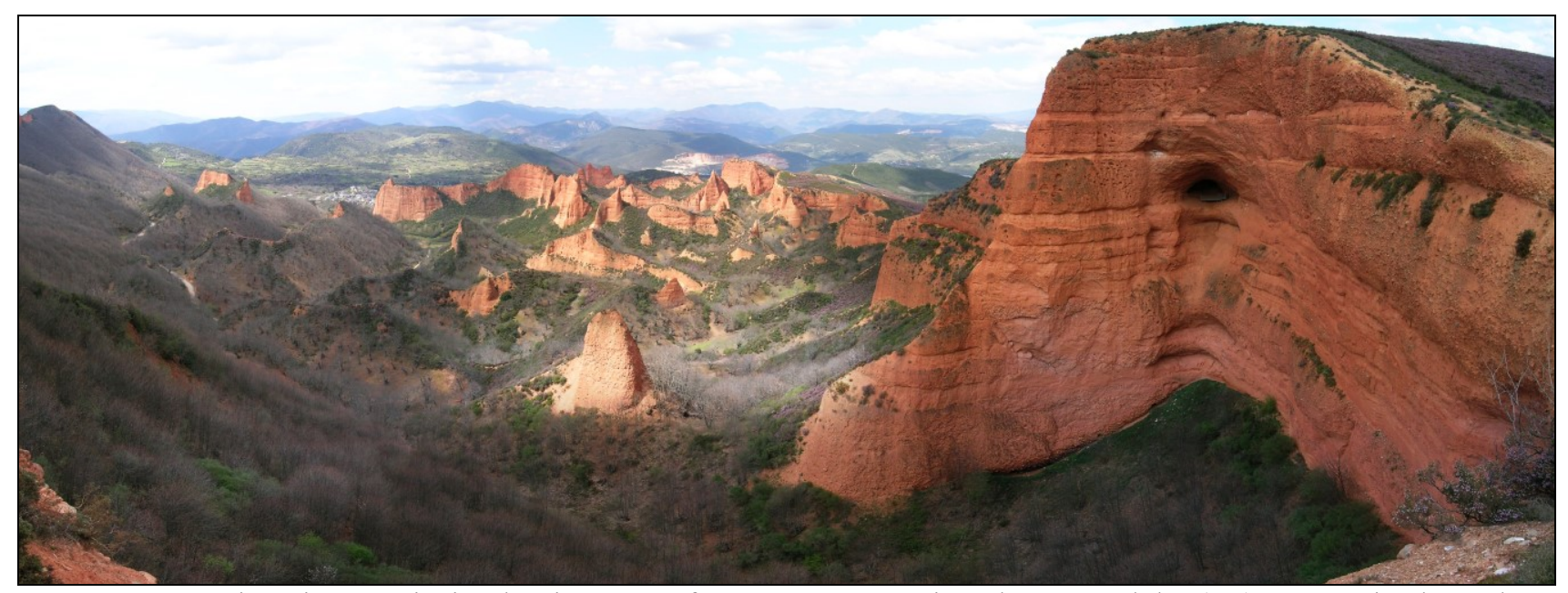

Figura 3 - Patrimônio Geomineiro do Tipo 2. Geoformas Antropogênicas de Las Médulas (ES), uma antiga lavra de ouro do período romano, ao longo dos séculos I e II D.C.

Fonte: Alessio Damato.

Na Serra de Ouro Preto houve um intenso processo extrativo de ouro entre os séculos XVII e XIX. Diversos processos de mineração foram empregados ao longo de cerca de $7 \mathrm{~km}$ no flanco sul da serra. Os serviços de lavra se entremeavam com as habitações, que após o esgotamento operacional das minas avançaram sobre as áreas mineradas e sobre as escombreiras, compondo a paisagem atual, onde expressiva parte da população da cidade de Ouro Preto reside (SOBREIRA 2014). Processo semelhante ocorreu na Serra de Antônio Pereira, porém sem a intensidade com que aconteceu na Serra de Ouro Preto. Naquela serra, somente no povoado de Antônio Pereira e em algumas áreas da cidade de Mariana a remoção de rochas e a modificação da paisagem se deu em intensidades similares às da Serra de Ouro Preto (NASCIMENTO, 2016).

As paisagens geomineiras não se restringem somente às zonas de ocorrência de metais de grande valor por unidade de peso. Há casos em que a necessidade de algum recurso mineral, devido à escassez de produtos utilizados para o mesmo fim, como é o caso dos georrecursos energéticos como o linhito em Minas Gerais no início do século XX em substituição ao petróleo. Houve explotação intensa deste recurso mineral na Bacia Sedimentar Cenozoica do Gandarela, próximo à Belo Horizonte que modificou intensamente a paisagem, expondo em frentes de lavras linhitos, 
interestratificados com lamitos fossilíferos, afloramentos únicos deste tipo na região Maizatto (2001). Paisagens do tipo dois estão sendo formadas nesta década ao longo das serras que compõem o Planalto do Espinhaço, próximo à cidade de Guanhães, em Minas Gerais, devido à extração de quartzitos e quartzo.


Figura 4 - Patrimônio Geomineiro do Tipo 2. A esquerda, imagem da Serra de Ouro Preto evidenciando as zonas de ocupação urbana entremeadas com áreas de desmontes causados pela mineração de ouro ao longo do século XVIII (Google Earth, 2016). A direita, Detalhes de parte da Serra, mostrando as áreas de grande rugosidade, que são resultantes dos desmontes trabalhos de mineração nos bairros de Alto da Cruz e Padre Faria; ao fundo o Morro da Queimada.

Dois exemplos representativos do tipo 3 de patrimônio geomineiro vinculado à geomorfologia antropogênica são aqueles que ocorreram na região de Igatu, povoado localizado no município de Andaraí (Ba) e o Monumento Natural de Cierro del Hierro, no Parque Natural Serra Norte de Sevilha (ES).

Em Igatu, e em boa parte do flanco oriental da Chapada Diamantina, os trabalhos de extração tradicional do diamante e carbonado, variedade amorfa do diamante, modificaram profundamente a paisagem, criando uma cultura regional bastante peculiar (NOLASCO, 2012). Posto que o diamante tem seu valor relacionado ao volume das pedras, os processos de garimpagem ocorreram em material desagregável, decorrente dos processos intempéricos e erosivos sobre as rochas sedimentares que os abrigavam. Assim, o garimpo tradicional ocorria em colúvios e em alúvios de drenagens de pequena ordem, que se acumularam sobre substrato rochoso proterozoico, nas falhas e fraturas. A remoção destes sedimentos pouco consolidados foi intensa e atingiu o material pedogenizado que sustentava a vegetação primeva da região, exumando a superfície que marcava a interface rocha material friável. Nolasco (2012) e Russ \& Nolasco (2012) descrevem os processos e as transformações da paisagem e a geração de geoformas antrópicas, representadas pela superfície exumada e suas alterações, com modificações profundas no sistema natural (Figura 5) 

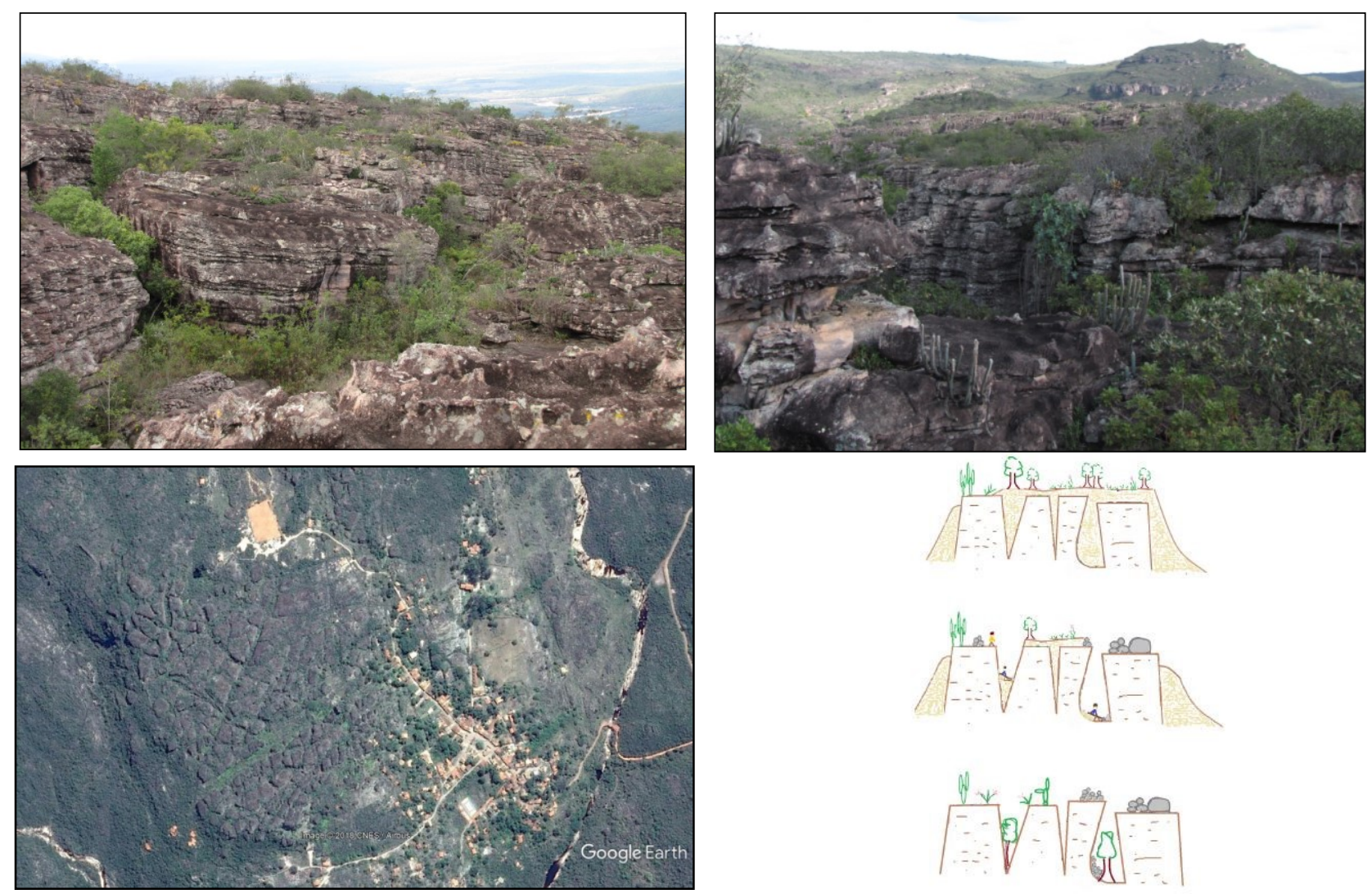

Figura 5 - Patrimônio Geomineiro do Tipo3. As fotos acima mostram a paisagem atual da região, evidenciando as exposições rochas com cobertura vegetal arbustiva e a vegetação arbórea ocupando as depressões causadas pelo esvaziamento das fraturas e retirada do material colúvio-aluvial pelo garimpo. Abaixo, a esquerda a vila de Igatu e a paisagem antropogênica gerada pela ação extrativa do diamante e carbonado (Google Earth, 2018). À direita, esquema evolutivo da ação garimpeira ao longo de 200 anos e a geração da paisagem atual, no desenho inferior (RUSS; NOLASCO, 2012). resultantes dos desmontes trabalhos de mineração nos bairros de Alto da Cruz e Padre Faria; ao fundo o Morro da Queimada.

O Monumento Natural Cierro del Hierro mostra a exumação de um paleocarste realizado pela mineração de ferro que aconteceu ao longo do da era cristã, atingindo o auge no século XIX e encerrando suas atividades na segunda metade do século XX. O ferro se concentrou em uma superfície de descontinuidade estratigráfica entre os calcários eocambrianos e os lamitos neocambrianos, que são representados por uma exposição subaérea dos calcários e desenvolvimento de um carste que se formou em quatro etapas: no Cambriano, no Carbonífero; já no Paleógeno houve nova exposição subaérea que causou a mais extensa carstificação regional, seguida de processos cársticos menos desenvolvidos na atualidade (MORENO et al., 2008). Os minerais de ferro se depositaram nos lamitos que preencheram o carste, sobretudo o formado no Cambriano, e que aumentaram a sua concentração entre o Devoniano e o Permiano por enriquecimento devido à circulação de fluidos. A exploração de ferro exumou, em parte significativa as feições exocarste formadas no Paleógeno e expondo também algumas feições cársticas formadas no Cambriano (Figura 6). 

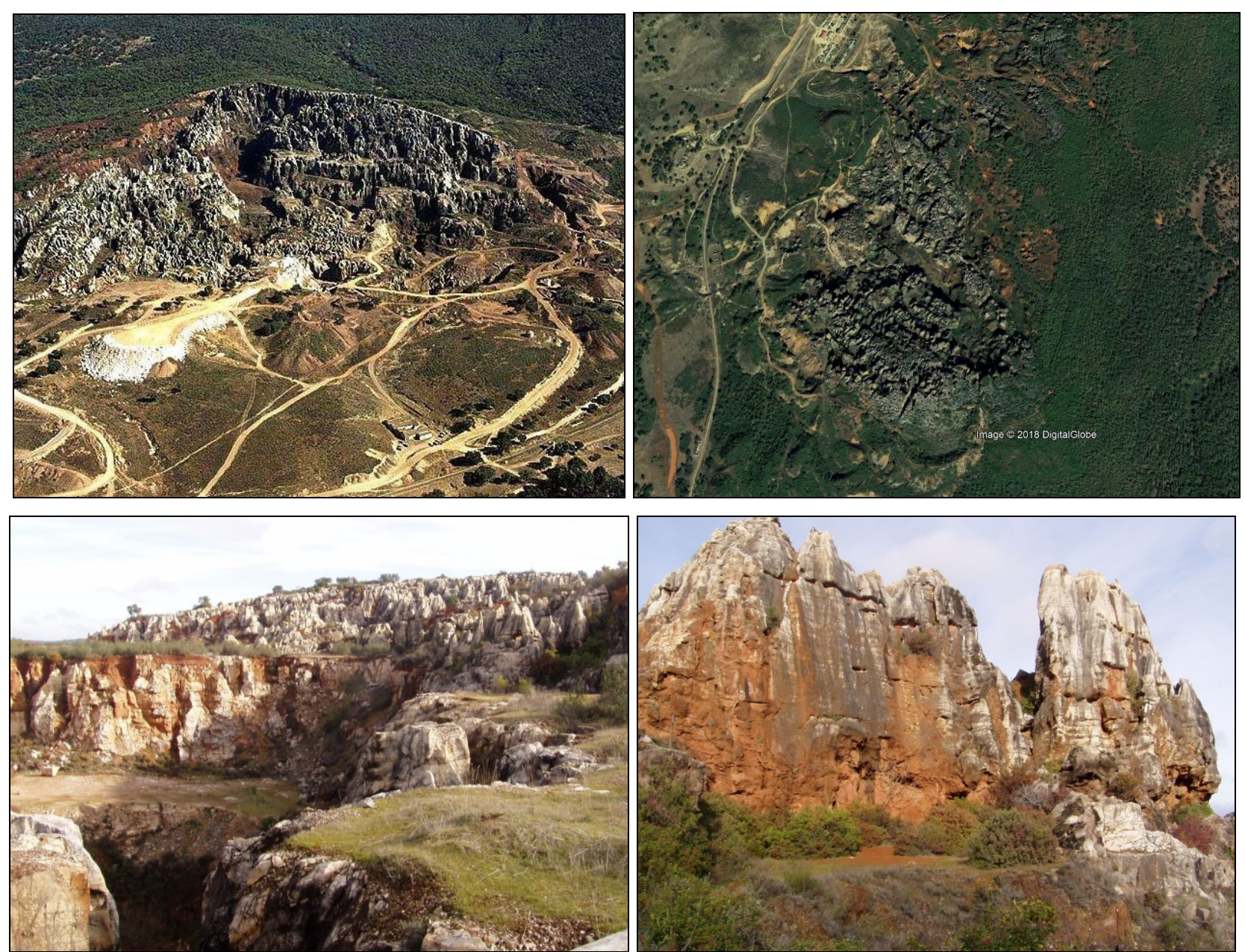

Figura 6 - Patrimônio Geomineiro do Tipo3. As fotos superiores mostram as características gerais da área exumada, que foi gerada pelas atividades mineiras em Cerro del Hierro, Espanha (foto da esquerda J. Alonso; direita Google, 2018). As fotos inferiores mostram feições do paleocarste paleogênico exumado, com esvaziamentos de cavidades pelo processo de extração.

\section{CONSIDERAÇÕES FINAIS}

Os significados de Geopatrimônio e Patrimônio Mineiro têm percorrido caminhos paralelos ao longo do desenvolvimento conceitual. Isto se deve, em parte, à segmentação dos campos de conhecimento, em que há uma tendência a separação da análise do que é relacionável a patrimônio da humanidade em dois segmentos, o natural e o cultural. Além disto, o entendimento dos registros dos processos de transformação industrial da natureza teve um longo caminho até o entendimento de ser expressão cultural. A literatura relativa à evolução histórica do conceito de patrimônio mineiro abrangeu inicialmente os procedimentos da mineração, principalmente a mineração histórica. Posteriormente, abarcou o modo de viver, os valores dos povos de regiões mineiras, ou seja, a cultura mineira, como expressão de uma coletividade e, portanto, seu patrimônio. Posteriormente, foram entendidos os documentos das indústrias mineiras como parte do patrimônio e, mais recentemente a paisagem, englobando o aspecto natural, transformado pela mineração, com 
suas edificações industriais e domiciliares, seu modo de construção, como parte do patrimônio mineiro (PUCHE RIART, 2000).

Por outro lado, a origem do geopatrimônio e sua importância se deu a partir do entendimento de que exemplos relevantes de materiais geológicos (in situ e ex situ), as geoformas e seus processos formadores passam a ser importantes, pois refletem e contam a história da Terra. Sua origem se dá pela incorporação ao entendimento de patrimônio natural da componente abiótica, seguindo os passos da humanidade em conservação da natureza biótica a partir de meados do século $\mathrm{XX}$.

A conexão entre o Geopatrimônio e o Patrimônio Mineiro começou a surgir após a aplicação do conceito de paisagem, incorporando o natural e o antrópico e a constatação de que ser o ser humano um agente geológico capaz de transformar o planeta Terra (visão fundamentada em VERNADSKY, 1998) e de contribuir para a geração de formas de relevo antrópicos, fundamentando a geomorfologia antropogênica. Este texto traz uma tentativa de compreensão dos diferentes tipos de Patrimônio Geomineiro gerado a partir da geomorfologia antropogênica.

\section{REFERÊNCIAS}

BRILHA, J. Geoheritage: inventories and evaluation. In: REYNARD, E.; BRILHA, J. Geoheritage: Assessment, Protection, and Management. Amsterdam: Elsevier, 2018, p. 69-86.

CAÑIZARES RUIZ, M. C. Protección y Defensa del Patrimonio Minero en España. Scripta Nova.

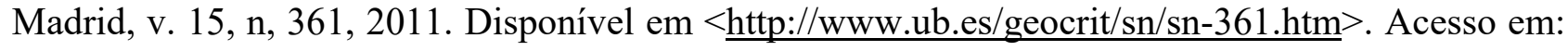
3 nov. 2018.

CASTRO, P. T. A.; MACHADO, M. M. M. Os conflitos resultantes da produção de minério de ferro. In: RUCHKYS, U. A.; TRAVASSOS, L. E. P.; RASTEIRO, M, A.; FARIA, L. E. Patrimônio Espeleológico em Rochas Ferruginosas - Propostas para a sua conservação no Quadrilátero Ferrífero, Minas Gerais. Campinas: Sociedade Brasileira de Espeleologia, 2015. p. 116-131.

GOUDIE, A.S. Human influence in geomorphology. Geomorphology, Nova Iorque, v. 7, n. 1-3, p. 37-59, 1993.

GUTIÉRREZ-MARCO, J. C.; SÁ, A. A.; GARCÍA-BELlIDO, D. C.; RÁBANO, I.; VALÉRIO, M. Giant trilobites and trilobite clusters from the Ordovician of Portugal. Geology. Nova Iorque, v. 37, p. 443-446, 2009.

MACIEL, V. M. Análise da geodiversidade da bacia do rio Maracujá, e suas adjacências, nos arredores de Santo Antônio do Leite e Cachoeira do Campo. 2014. 79 f. Monografia (Trabalho de Conclusão de Curso em Engenharia Geológica) - Escola de Minas, Universidade Federal de Ouro Preto, Ouro Preto, 2014. 
MAIZATTO, J. R. Análise bioestratigráfica, paleoecológica e sedimentológica das bacias terciárias do Gandarela e Fonseca - Quadrilátero Ferrífero - Minas Gerais, com base nos aspectos palinológicos e sedimentares. 2001. 249 f. Dissertação (Mestrado em Programa de PósGraduação em Evolução Crustal e Recursos Naturais) - Escola de Minas, Universidade Federal de Ouro Preto, Ouro Preto, 2001.

MATA-PERELLÓ, J.; CARRIÓN, P.; MOLINA, J.; VILLAS-BOAS, R. Geomining Heritage as a Tool to Promote the Social Development of Rural Communities. In: REYNARD, E., BRILHA, J. Geoheritage: Assessment, Protection, and Management. Amsterdam: Elsevier, 2018, p. 167177.

MATA-PERELLÓ, J.; MATA-LLEONART， R.; VINTRÓ-SÁNCHEZ， C.; RESTREPOMARTÍNEZ, C. Social Geology: a new perspective on geology. Dyna, Medelin, v. 79, p. 158-166, 2012.

MIGORI, P. Geoheritage and World Heritage Sites. In: REYNARD, E.; BRILHA, J. Geoheritage: Assessment, Protection, and Management. Amsterdam: Elsevier, 2018, p. 237-249.

MORENO, C. G.; SÁEZ, R. R.; GONZÁLEZ, F. B. Guia geológica e itinerários: Parque Natural Sierra Norte de Sevilla. Consejería de Medio Ambiente, Red de Espacios Naturales Protegidos. Sevilha, 2018, 210p.

NASCIMENTO, M. A. L.; ROCHA, A. J. D.; NOLASCO, M. C. Patrimônio geológico e mineiro no nordeste do Brasil. Boletim Paranaense de Geociências, Curitiba, v. 70, p. 103-119, 2013.

NASCIMENTO, S. T. Geodiversidade e geomorfologia antropogênica na região das minas de ouro no anticlinal de Mariana, MG. 2016. 88 f. Dissertação (Mestrado em Evolução Crustal e Recursos Naturais) - Escola de Minas, Universidade Federal de Ouro Preto, Ouro Preto, 2016.

NIR, D. Man, a geomorphological agent. Jerusalém: Keter Publishing House, 1983, 165p.

NOLASCO, M. C. Paisagens a Diamante: Chapada Diamantina, BA. In: CONGRESO INTERNACIONAL SOBRE PATRIMONIO GEOLÓGICO Y MINERO, 13., 2012, Manresa. Anais... Manresa 2012, p. 345-378.

PROBIERZ, K. Las Médulas (Hiszpania), dawna kopalnia zlota. Przeglad Geologiczny, v. 60, p. 480-484, 2012.

PUCHE RIART, O. Patrimonio minero-metalúrgico español: arquitectura y paisajes mineros. In: CONGRESO INTERNACIONAL SOBRE PATRIMONIO GEOLÓGICO Y MINERO, 4., 2003, Barcelona, Actas... Barcelona: SEDPGYM, 2003, p. 57-68.

PUCHE RIART, O. La conservación del Patrimonio Geológico y Minero. Estudio e investigación en Ciencias de la Tierra, Madrid, p. 73-101, 2000.

PUCHE RIART, O.; GARCIA CORTÉS, A.; MATA PERELLÓ, J. M. Conservación del patrimonio histórico minero-metalúrgico español. In: CONGRESO INTERNACIONAL DE MINERÍA Y METALURGÍA, 11., 1994, León, Actas... León, 1994, p. 433-448.

REDONDO-VEGA, J. M.; ALONSO-HERRERO, E.; SANTOS-GONZÁLEZ, J.; GONZÁLEZGUTIÉRREZ, R. B.; GÓMEZ-VILLAR, A. La Balouta exhumed karst: a Roman gold-minederived landscape within the Las Médulas UNESCO World Heritage Site (Spain). International Journal of Speleology, v. 44, n. 2, p. 267-276, 2015. 
REYNARD, E.; BRILHA, J. Geoheritage Assessment, Protection, and Management. Amsterdam: Elsevier, 2018. 450p.

RUCHKYS, U. A. Patrimônio geológico e geoconservação no Quadrilátero Ferrífero, Minas Gerais: potencial para criação de um geoparque da UNESCO. 2007, 201 f. Tese (Doutorado em Geologia) - Instituto de Geociências, Universidade Federal de Minas Gerais, Belo Horizonte, 2007.

RUCHKYS, U. A.; CASTRO, P. T. A.; SANTOS, D. J.; RODRIGUES, J. S. B. Patrimônio em geossistemas ferruginosos: potencial de uso para o geoturismo. Revista Latino-Americana de Estudos em Cultura e Sociedade, v. 04, n. 2, p. 1-20, 2018.

RUCHKYS, U. A.; MACHADO, M. M. M.; CASTRO, P. T. A.; RENGER, F. E.; TREVISOL, A. Geoparque Quadrilátero Ferrífero, Minas Gerais. In: SHOBBENHAUS, C.; SILVA, C. Geoparques do Brasil: propostas. Rio de Janeiro: Serviço Geológico do Brasil, 2012. p. 183-220.

RUSS, B. R.; NOLASCO, M. C. Vila de Igatu, Bahía, Brasil: historia ambiental del patrimonio geominero de diamantes, 1846-2012. In: CONGRESO INTERNACIONAL SOBRE PATRIMONIO GEOLÓGICO Y MINERO, 13., 2012, Manresa. Actas... Manresa: 2012, p. 401422.

SANCHEZ-PALENCIA, F. J.; FERNANDEZ-POSSE, J.; FERNANDEZ MANZANO, A. O.; PEREZ GARCIA, L. C. Las Médulas (León), La formación de un Paisaje Cultural Minero. Boletín Geológico y Minero, v. 109, p. 589-598, 2000.

SOBREIRA, F. G. Mineração do ouro no período colonial: alterações paisagísticas antrópicas na serra de Ouro Preto, Minas Gerais. Quaternary and Environmental Geosciences, v. 5, n. 1. 2014. Disponível em < revistas.ufpr.br/abequa/article/download/34432/23233> Acesso em: 12 nov. 2016.

SOTCHAVA V. B. O estudo dos geossistemas. Métodos em Questão. 6. ed. São Paulo, 1977. 50p.

SZABÓ, J.; LÓRANT, D.; LÓCZY, D. Anthropogenic Geomorphology: a guide to man made landforms. Londres: Springer, 2010. 260p.

VERNADSKY, V. I. The biosphere. Nova York: Copernicus, 1998. 192p.

VITTE, A. C. O desenvolvimento do conceito de paisagem e a sua inserção na geografia física. Mercator, v. 6, n. 11, p. 71-78. 2007.

ZAMORA, E. A. Sobre patrimonio y desarrollo: Aproximación al concepto de patrimonio cultural y su utilización en los procesos de desarrollo territorial. Pasos: Revista de Turismo y Patrimonio Cultural, v. 9, n. 1, p. 101-113. 2011. 